\title{
SHORT COMMUNICATION UNVACCINATED CHILD TETANUS FROM NASAL TOY BATTERY
}

\author{
Lukáš Homola ${ }^{1}$, Josef Klučka², Jan Helešic ${ }^{1}$, Zlata Jirsenská1, Milan Kratochvíl', Petr Dominik², Milan Urík ${ }^{3}$, \\ Ondřej Horák ${ }^{4}$, Petr Jabandžiev ${ }^{5}$, Lenka Krbková1, Petr Štourač \\ ${ }^{1}$ Department of Children's Infectious Diseases, University Hospital Brno and Faculty of Medicine, Masaryk University, Brno, Czech Republic \\ ${ }^{2}$ Department of Paediatric Anaesthesia and Intensive Care Medicine, University Hospital Brno and Faculty of Medicine, Masaryk University, \\ Brno, Czech Republic \\ ${ }^{3}$ Department of Paediatric Otorhinolaryngology, University Hospital Brno and Faculty of Medicine, Masaryk University, Brno, Czech Republic \\ ${ }^{4}$ Department of Neurology, University Hospital Brno and Faculty of Medicine, Masaryk University, Brno, Czech Republic \\ ${ }^{5}$ Department of Paediatrics, University Hospital Brno and Faculty of Medicine, Masaryk University, Brno, Czech Republic
}

\section{SUMMARY}

We present the case report of an unvaccinated Czech child with tetanus. The child had not received any vaccines due to its parent's refusal. The disease originated from the wound in the nose caused by a small flat battery. The typical onset of tetanus followed after two weeks, rapidly progressing to respiratory failure with the need for mechanic ventilation despite intensive treatment. The child spent five weeks in the hospital. Mild long-term sequelae persisted 5 months.

Key words: tetanus, intensive care, paediatric patient

Address for correspondence: P. Dominik, University Hospital Brno, Department of Paediatric Anaesthesia and Intensive Care Medicine, Černopolní 9, 61300 Brno, Czech Republic. E-mail: dominik.petr@fnbrno.cz

https://doi.org/10.21101/cejph.a6702

\section{INTRODUCTION}

Tetanus is a disease caused by Clostridium tetani toxin. Clostridia are ubiquitous bacteria frequently found in the bovine and human intestine. The usual source of the infection is the wound contaminated with soil. Tetanus is rare in developed countries due to widespread vaccination; however, sporadic cases occur in unvaccinated children, in individuals with waned immunity or specific risky behaviour (1).

In September 2019, a two and half year-old boy came to the University Hospital Brno with symptoms of tetanus. The case started two weeks earlier when he inserted a small flat toy battery to his nose. Parents noticed and took the boy to otorhinolaryngology (ENT) for extraction. Parents estimate the time from insertion to extraction to be only two hours. There was already a deep erosion in the nasal mucosa at the time of extraction. The parents did not notify the ENT physician that the child was not vaccinated, so no tetanus prophylaxis was administered. The boy returned to ENT for frequent follow-up visits in the next two weeks. Necrosis of nasal septum complicated the wound healing, so ENT prescribed cefuroxime-axetil, but parents did not give it to the boy.

Two weeks after the wound, the symptoms of tetanus started with grinning expression and prominent fatigue. Symptoms were worsening to the difficulty of swallowing and trismus. The child was sent and admitted to the hospital after four days. Tetanus treatment was initiated immediately.
To exclude other possible causes, we performed an extensive set of diagnostic tests. No pathologies were present in serum, urine, cerebrospinal fluid, or the magnetic resonance of the brain.

Video electroencephalography captured typical tonic episode with opisthotonus triggered by drinking (Supplementary material 1).

Zero serum levels of tetanus antibodies before the therapy confirmed the unvaccinated status.

At the time of admission, symptoms were mild, but during the first night, the disease progressed to episodes of tonic seizures with typical opisthotonus. Attempts to drink triggered muscle spasms. Benzodiazepines were administered for tonic seizures treatment. Antitetanic globulin and tetanic vaccination were administered together with antibiotics against Clostridium tetani (clindamycin + metronidazole). In four days, despite repeated high doses of antitetanic globulin, magnesium (with target plasmatic concentration of $\geq 2 \mathrm{mmol} / \mathrm{L}$ ), and benzodiazepines, because of spasms cumulation and respiratory failure patient was intubated and mechanically ventilated. Several attempts of weaning from sedative medication and mechanical ventilation failed due to the rapid occurrence of muscle spasms after reducing the level of sedation.

Typical opisthotonus was recorded during weaning attempt (Fig. 1).

After eight days, the patient weaned successfully from mechanical ventilation. Intensive breathing rehabilitation, including 


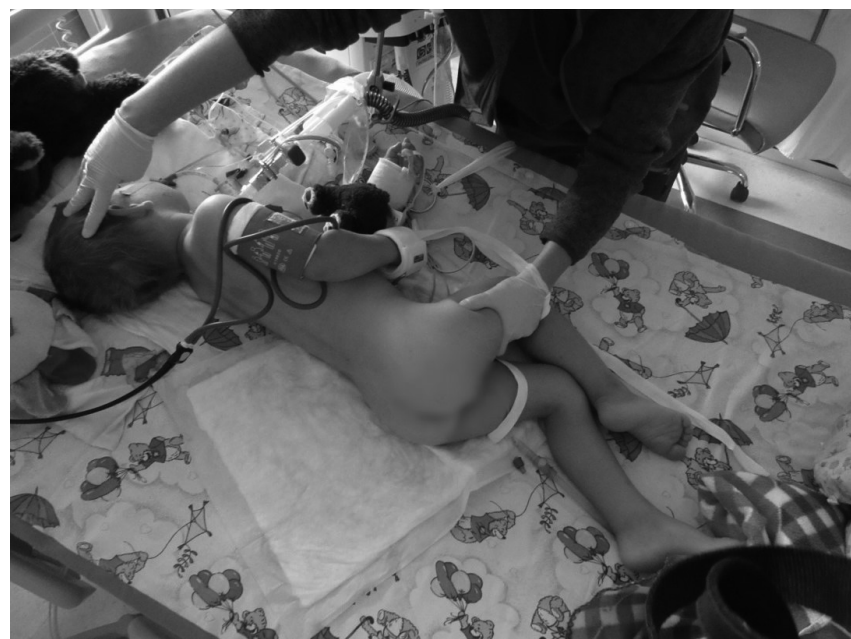

Fig. 1. Opisthotonus.

vibration, was necessary due to insufficient airway secretion clearance. After extubation, the condition was gradually improving. The number of trismus was progressively reducing with no documented case of opisthotonus after extubation.

Five weeks of slow recovery followed. Trismus lasted two weeks.

Risus sardonicus was recorded during slow recovery phase (Fig. 2).

Swallowing difficulty persisted three weeks and the inability to walk four weeks. The boy left the hospital after five weeks.

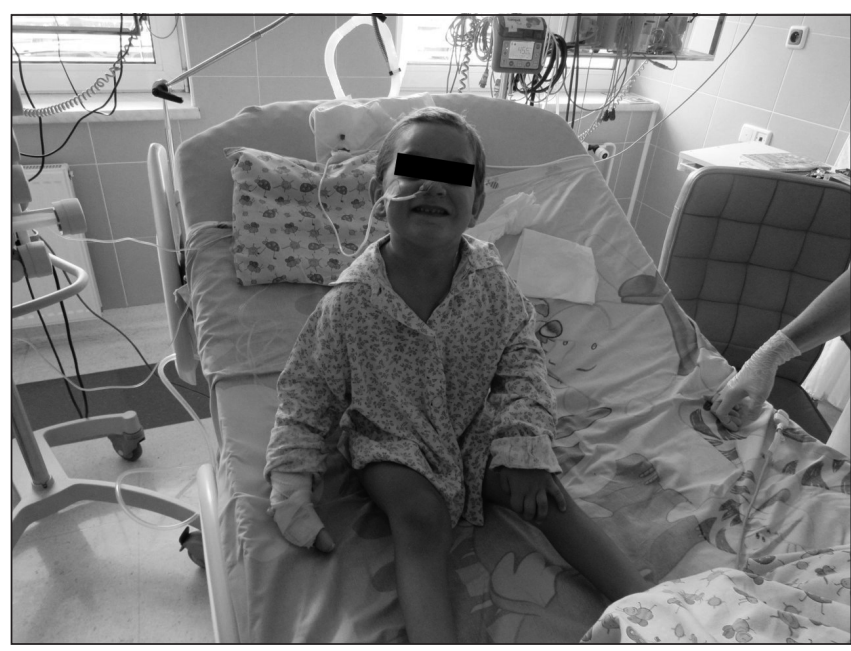

Fig. 2. Risus sardonicus.

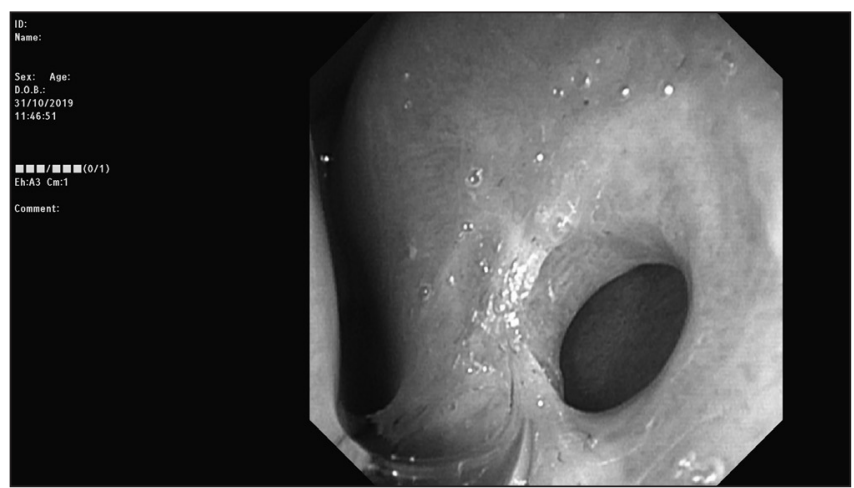

Fig. 3. Septum.
Central hypotonic syndrome and walking on a broad base was present at the time of discharge (Supplementary material 2).

Permanent hole in the nasal septum was recorded two months after battery removal (Fig. 3).

Mild unsteady walking and leg hyper-reflexion persisted after five months. The follow-up continued for 12 months until he was considered recovered.

\section{DISCUSSION}

Child tetanus cases in developed countries were rare in the past 20 years. We have found nine published cases (2-7), four were from Europe (2-5). The mean age of all cases was 4.7 years ranging from 16 months to 9 years.

An apparent injury caused most of them - hallux nail injury (4), cracks between toes (7), superficial heel laceration (7), knee injury (7), an iron gate thumb scratch (3), arm cut by the edge of a tile (2), a home-sutured laceration of forehead (6), and in one recent case - decayed teeth were possible entry points of infection (5). In our case, the apparent source of the infection is the battery wound in the nose. Whether the Clostridium tetani contaminated the wound from the beginning or it was contaminated later remains unclear. The family lives in a countryside house under reconstruction, so the frequent contact with the soil is probable. Like our case, many cases happened in the summer season $(2,3,5)$.

The diagnose of tetanus was based on a typical course of the disease and per exclusion of other causes. However, we do not have any microbiological evidence of Clostridium tetani.

All reported cases were related to inadequate vaccination. The reasons for non-proper immunization were parents refusing vaccination (2-7) sometimes combined with poor socioeconomic conditions (5). Also, in our case, the leading cause is the unvaccinated status of the child. The boy had not received any regular vaccination since the parents refused it. The reason for their refusal was a fear of multiple sclerosis (MS). The mother is suffering from MS, that was, in her opinion, caused by vaccination. After the case, parents slowly changed their opinion, and five months later, they agreed with partial vaccination of their children.

In all published cases, children survived after prolonged intensive hospital care. Most have recovered fully $(2-4,6,7)$; few had long term sequalae $(5,7)$. The boy recovered slowly, mild long-term consequences persisted for five months until finally achieving full recovery.

\section{CONCLUSION}

The hospital case cost was 19.500 Euro (the care after discharge not included) that can be considered rather low in terms of medical costs of some other cases (6). However, it is still striking compared to the cost of the tetanus vaccine (5 Euro).

\section{Electronic Supplementary Materials}

1. EEG of tetanic paroxysm: http://video.muni.cz/public/akutne.cz/ CEJPH/CEJPH-Tetanus-Supplementum-1.mp4

2. Post-tetanus unsteady walk: http://video.muni.cz/public/akutne.cz/ CEJPH/CEJPH-Tetanus-Supplementum-2.mp4 


\section{Acknowledgement}

Supported by MH CZ - DRO (FNBr, 65269705)

\section{Conflict of Interests}

None declared

\section{Adherence to Ethical Standards}

The legal representative of the patient signed the informed consent with the publication of recorded materials.

\section{REFERENCES}

1. Hahné SJ, White JM, Crowcroft NS, Brett MM, George RC, Beeching NJ, et al. Tetanus in injecting drug users, United Kingdom. Emerg Infect Dis. 2006;12(4):709-10.
2. Koliou M, Ioannou Y, Stylianidou G. A case of childhood tetanus in Cyprus in 2003: a rarely seen disease. Euro Surveill. 2007 Feb 8;12(2):E070208.5. doi: 10.2807/esw.12.06.03136-en.

3. Giovanetti F, Pellegrino A. A case of tetanus in a child whose parents refused immunization - Piedmont Region, Italy, 2006. Euro Surveill. 2007 Jun 21;12(6):E070621.2. doi: 10.2807/esw.12.25.03223-en.

4. de Jong PR, de Heer-Groen T, Schröder CH, Jansen NJ. Generalized tetanus in a 4-year old boy presenting with dysphagia and trismus: a case report. Cases J. 2009 Apr 29;2:7003. doi: 10.1186/1757-1626-2-7003.

5. Urbančíková I, Pisarčíkova M, Tischler G, Bazárová K, Hudáčková D. Tetanus in Slovakia. Vakcinologie. 2018;12(1):20-5. (In Slovak.)

6. Guzman-Cottrill JA, Lancioni C, Eriksson C, Cho YJ, Liko J. Notes from the field: tetanus in an unvaccinated child - Oregon, 2017. MMWR Morb Mortal Wkly Rep. 2019 Mar 8;68(9):231-2.

7. Wen SC, Webb C, Miles F, Wilson E. Tetanus in New Zealand children: intensive care management of a vaccine preventable disease. J Paediatr Child Health. 2016 Dec;52(12):1070-4.

Received February 9, 2021 Accepted in revised form December 5, 2021 